\title{
Supernumerary kidney laparoscopically treated
}

\author{
Michele Innocenzi, MD; ${ }^{*}$ Paolo Casale, MD; ${ }^{\dagger}$ Andrea Alfarone, MD; ${ }^{*}$ Michele Ravaziol, MD;* \\ Susanna Cattarino, MD; ${ }^{*}$ Pietro Grande, MD; Francesco Minisola, MD; ${ }^{*}$ Alessandro Gentilucci, MD;* \\ Vincenzo Gentile, MD; ${ }^{*}$ Alessandro Sciarra, $M D^{*}$
}

*Dipartimento di Scienze Ginecologico Ostetriche e Scienze Urologiche, Università di Roma "La Sapienza," Rome, Italy; ‘'Azienda Ospedaliera universitaria di Pisa, Pisa, Italy

Cite as: Can Urol Assoc J 2013;7(11-12):e772-4. http://dx.doi.org/10.5489/cuaj.788 Published online November 8, 2013.

\section{Abstract}

Congenital anomalies of the kidney and urinary tract are part of a family of diseases with different anatomical origins. Duplicated collecting systems can be defined as a renal unit containing 2 pyelocalyceal systems associated with a single ureter or with double ureters. The supernumerary kidney is a definitive accessory organ with its own collecting system, blood supply, and distinct encapsulated parenchima. The true incidence of supernumerary kidney remains unknown, but most cases are in males, are unilateral and on the left side. We present a case of an adult woman with a hypoplastic supernumerary kidney with a complete ureteral duplication and an ectopic junction. The case has been laparoscopically treated. We demonstrate that a laparoscopic nephro-ureterectomy is feasible and that the management of the complication (urinoma and fistula) can be managed conservatively.

\section{Introduction}

Congenital anomalies of the kidney and urinary tract are part of a family of diseases with different anatomical origins, including kidney anomalies, such as multicystic dysplastic kidney, hypoplastic kidney, ureteropelvic junction obstruction, vescicoureteral reflux, megaureter, and anomalies of the bladder and urethra. ${ }^{1}$

Some of these anomalies are often concurrent. Renal hypoplasia and dysplasia are often accompanied by vescicoureteral reflux or ureteropelvic junction obstruction that involve the ipsilateral or contralateral kidney. ${ }^{2}$ Duplicated collecting systems can be defined as a renal unit containing 2 pyelocalyceal systems associated with a single ureter or with double ureters. ${ }^{3}$

The supernumerary kidney is a definitive accessory organ with its own collecting system, blood supply, and distinct encapsulated parenchima. This anomaly is present at birth, it is rarely symptomatic, but may become symptomatic in early adulthood. ${ }^{4}$

We present a case of an adult woman with a hypoplastic supernumerary kidney with a complete ureteral duplication and an ectopic junction. She was laparoscopically treated.

\section{Case report}

In October 2011, a 29 year-old woman with chronic urinary infections and flank pain was diagnosed with a right renal mass via an abdominal ultrasonography. Her magnetic resonance imaging (MRI) showed a complete duplicated collecting system with ectasia of the superior district and long washing-out. Using Tc99-mercaptoacetyltriglycine renal scintigraphy to determine the glomerular filtration rate, the preoperative unilateral renal function was determined to be $56 \%$ (left side) and $44 \%$ (right side) with a $95.4 \mathrm{~mL} / \mathrm{min}$ global function. After counselling the patient, we performed a cystoscopy and a retrograd pyelography (Fig. 1, part A) that revealed a duplicated right ureter with a dilated ectopic ureteric orifice into the urethra.

Before planning the surgery, we studied the anatomical and vascular aspects of the right kidney with a MRI that confirmed a complete duplicated system with a nonfunctioning upper pole renal unit related to an ectopic ureteric orifice into the pre-sphincteric urethra (Fig.1, part B). After obtaining the patient's consent, we proceeded with a laparoscopic partial nephrectomy (December 2011). The patient was positioned in the $45^{\circ}$ modified flank position and an intraperitoneal access was used. After reflecting the colon medially, both ipsilateral right duplicated ureters were identified, with distinction between the 2 through the dilatation and the presence of a previously positioned ureteral catheter in the upper pole ectopic ureter. After isolation of the renal hilum, the upper pole ureter was dissected toward the hilum and the atrophic upper pole of the kidney was isolated. 


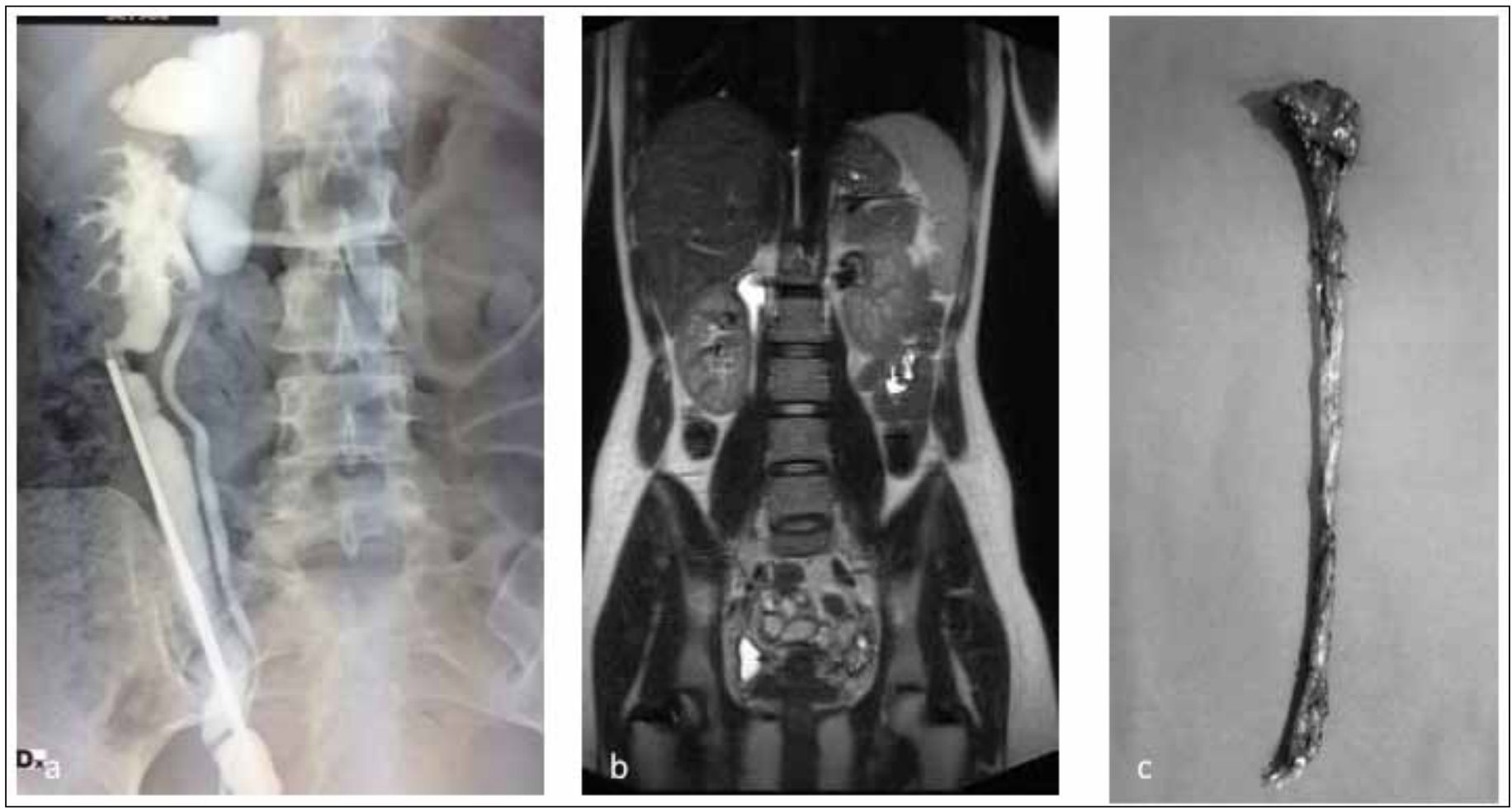

Fig. 1. (A) Diagnostic retrograd pyelography that revealed a duplicated right ureter with one dilated ectopic ureteric orifice into the urethra. (B) Preoperative magnetic resonace that confirmed a complete duplicated system with a nonfunctioning upper pole renal unit related to an ectopic ureteric orifice into the pre-sphincteric urethra. (C) Atrophic kidney with his ureter at surgery.

The renal upper pole was then excised along the atrophic cleavage plane using a ligasure device. No bleeding was found and further hemostatis was achieved with a cellulose hemostatic agent. Finally, the ureter was transected lower than the iliac vessels after closing with an hemolock. A closed suction drainage was placed in the surgical field before closure (Fig. 1, part C). The postoperative time was regular and the ureteral stent, catheter and drainage were removed on postoperative day 3 . The histological diagnosis was compatible with hypoplastics supernumeral kidney characterized by arteriosclerosis, tubular thyroidization and focal chronic inflammatory infiltrates. After 3 months (March 2012), she returned to our observation for flank pain and a computed tomography $(\mathrm{CT})$ study revealed a urinoma of $11 \times 9 \mathrm{~cm}$ with communication with the upper pole of the right kidney (Fig 2, part A). Urinoma was managed by ultrasound guided of drainage and a double $\mathrm{J}$ ureteral stent was positioned in the right ureter. After 1.5 months, am MRI showed no fluid cavities or persistant urinoma (Fig. 2, part B). The stent and drainage were removed without other complications.

At her last follow-up visit (September 2012), ultrasonography and MRI showed a small capsulated cavity of $2 \mathrm{~cm}$ positioned over the upper pole of the kidney that remained movable (Fig. 2, part C). The patient was also fully asymptomatic.

\section{Discussion}

Supernumerary kidney is among the rarest congenital urological anomalies with fewer than 100 cases reported in the English literature. ${ }^{4}$ The embryological anomaly is from premature division of the metanephric bud; the number of kidneys probably reflects the number of abnormal divisions of the progenitor cells. It affects males and females equally, and usually affects the left side. ${ }^{5}$

Although supernumerary kidney is rare and often underestimated, it is generally diagnosed in young people; ${ }^{6}$ this is why a surgery, if necessary, must be performed using the less invasive technique available. In our case, we suspected supernumerary kidney during the laparoscopy. We also noticed a small upper pole kidney with a definite capsule. During the dissection, we found a clear cleavage plane between the kidney upper pole and the supernumerary kidney.

We demostrated that a laparoscopic nephro-ureterectomy is feasible and that complications (urinoma and fistula) can be managed conservatively, according to the experiences reported by Abboussaly and colleagues.?

The histological examination demostrated that this case, presenting two different complete collecting systems differentiated by a own capsule, can be considered a supernumerary kidney. CT scans and MRIs performed preoperatively 


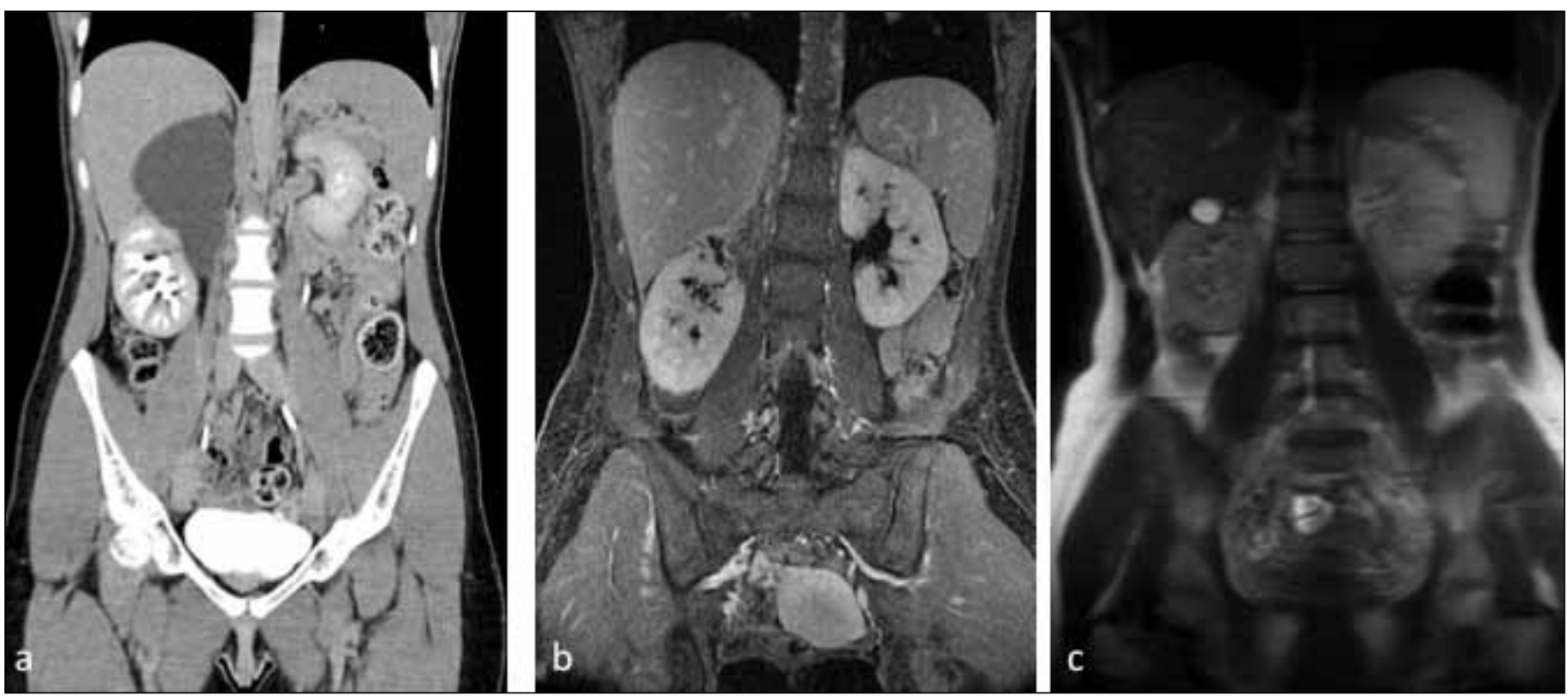

Fig. 2. (A) Postoperative computed tomography scan: urinoma after laparoscopic surgical treatment. (B) Postoperative magnetic resonance (MR): right kidney upper pole with evidence of urinary fistula. (C) Postoperative MR that showed an upper pole capsulated cavity of the right kidney with no further evidence of fistula or urinoma.

failed to differentiate the diagnosis with a duplicate collecting system in a simple kidney.

The development of urinoma postoperatively from upper pole makes us suspicious about whether there was any communication of the lower moiety with the upper one, which makes it a duplicated system rather than a supernumerary kidney. Nonetheless, the imaging reveals a complete set of calyces, which leads us to a supernumerary kidney; therefore, the urinoma is probably a consequence of a surgical injury.

\section{Conclusion}

CT scans, MRI and ultrasound performed postoperatively have always demonstrated the existence of a persistent complete right kidney, with the presence of all the calyceal groups, of the same size of the contralateral. This should confirm a supernumerary right kidney instead of a single duplicity of the collecting system of a single kidney.

Competing interests: Dr. Innocenzi, Dr. Casale, Dr. Alfarone, Dr. Ravaziol, Dr. Cattarino, Dr. Grande, Dr. Minisola, Dr. Gentilucci, Dr. Gentile and Dr. Sciarra all declare no competing financial or personal interests.
This paper has been peer-reviewed.

\section{References}

1. Brown T, Mandel J, Lebowitz R. Neonatal hydronephrosis in the era of sonography. Am J Roentgenol 1987;148:959-96. http://dx.doi.org/10.2214/air.148.5.959

2. Uetani $\mathrm{N}$, Bouchard M. Plumbing in the embryo: developmental defects of the urinary tracts. Clin Genet 2009;75:307-17. http://dx.doi.org/10.1111/i.1399-0004.2009.01175.x

3. Schlussel RN, Retik AB. Ectopic ureter, ureterocele, and other anomalies of the ureter, in Walsh PC (Ed): Campbell's Urology. Philadelphia, Saunders; 2002:2007-52.

4. Oto A, Kerimoglu U, Eskicorapci $S$, et al. Bilateral supernumerary kidney: Imaging findings. JBR-BTR 2002;85:300-3

5. Bernik TR, Ravnic DJ, Bernik SF, et al. Ectopic supernumerary kidney, a cause of para-aortic mass: Case report and review. Am Surg 2001;67:657-9.

6. Eberle J, Schwarz E, Abbrederis K. Kidney calculus episode in a supernumerary 3rd kidney. Urologe A 2002; 41:362-3

7. Abouassaly R, Gill IS, Kaouk JH. Laparoscopic Upper Pole Partial Nephrectomy for Duplicated Renal Collecting Systems in Adult Patients. Urology 2007;69:1202-5.

Correspondence: Dr. Michele Innocenzi, Dipartimento di Scienze Ginecologico Ostetriche e Scienze Urologiche, Universitò di Roma "La Sapienza," Rome, Italy; innocenzi.michele@gmail.com 